\title{
Sword of Damocles: application of the ethical principles of resource allocation to essential cancer surgery patients requiring beds in limited supply during the COVID-19 pandemic
}

\author{
Sammy Al-Benna $(\mathbb{D}$ \\ Received: 25 June 2020 / Accepted: 11 July 2020 / Published online: 7 August 2020 \\ (C) Springer-Verlag GmbH Austria, part of Springer Nature 2020
}

\section{Dear Editor,}

As a surge of COVID-19 (coronavirus disease 2019) patients strains the health care systems, shortages of health care professionals and life-saving equipment such as ventilators are forcing hospitals to make difficult decisions [1,2]. It is critical that these health care systems consider whether non-essential surgical procedures can be delayed to ration medical equipment and interventions [1, 2]. Theatre list shortages occur for many reasons, including lack of beds, lack of ventilators, lack of anaesthetic staff, lack of surgical staff, lack of nursing staff and material shortages (e.g. personal protective equipment) [1, 2]. Contributing to resource scarcity is the prolonged intubation many COVID-19 patients require as they recover from pneumonia, often two to three weeks, with several hours spent in the prone position and then, typically, a very slow weaning [1, 2]. During shortages, health care systems must determine how to fairly distribute these scarce resources to patients [3, 4]. Unfortunately, no single distribution framework applies to all shortages. However, general allocation principles for scarce health care resources, grounded in distributive justice and utility, can be applied, although particular rules will differ depending on the circumstances.

S. Al-Benna was actively involved in the planning, enactment and writing up of the study.

\section{S. Al-Benna $(\bowtie)$}

Division of Plastic and Reconstructive Surgery, Faculty of Medicine and Health Sciences, Stellenbosch University and Tygerberg Academic Hospital, Francie van Zijl Drive, PO Box 241, 8000 Cape Town, South Africa albenna@sun.ac.za

\section{Ethical principles of resource allocation for essential cancer surgery}

Surgery is the oldest modality of cancer therapy and still forms the mainstay of treatment for solid tumours [5]. Therefore, there is a demand for cancer surgery which may require beds, ventilators and health care professionals, including surgeons, anaesthetists and nurses. During the COVID-19 pandemic, priority should be given to those whose survival would benefit most from treatment to maximize benefit to society (Table 1 ; [6]). Applying this principle to surgical patients with cancer, only essential cancer surgery may proceed. Who are these patients? These are patients who cannot wait 3 months and are anticipated to gain a significant benefit from surgery. In addition, these patients will have no appropriate and comparable nonsurgical option available, and a 3-month delay will have a negative impact on their survival. In addition, palliative surgery for acute relief of pain and suffering of patients not controllable by nonsurgical means are allowed.

All clinicians must reassess allocation strategies as new data emerge. What is the mortality rate for COVID-19 patients who require mechanical ventilation? The Intensive Care National Audit and Research Centre (ICNARC) in the United Kingdom reported that of 165 patients admitted to ICUs, 79 (48\%) died [7]. Of the 98 patients who received advanced respiratory support, defined as invasive ventilation, BPAP or CPAP via endotracheal tube, or tracheostomy, or extracorporeal respiratory support, $66 \%$ died [7]. Compare that to the $36 \%$ mortality rate of non-COVID patients receiving advanced respiratory support reported to ICNARC from 2017 to 2019. The high death rate raises questions about how effective intensive care is in saving the lives of people with severe COVID-19. 
Table 1 The application of ethical principles of resource allocation in the COVID-19 pandemic. (Modified from Emanuel et al. [6])

\begin{tabular}{l|l}
\hline Ethical principle & Application to COVID-19 \\
\hline Maximize benefits & Saving the most lives/life-years is the highest priority \\
\hline $\begin{array}{l}\text { Treat people equally } \\
\begin{array}{l}\text { Promote and reward social } \\
\text { value }\end{array}\end{array}$ & $\begin{array}{l}\text { Random selection of patients with similar prognoses } \\
\text { With other factors equal, give priority to COVID-19 research participants }\end{array}$ \\
\hline Give priority to worst off & $\begin{array}{l}\text { Prioritisation to sickest and youngest of population if it aligns with maximizing benefits (for example, saving most years of life } \\
\text { or preventing further spread of virus) }\end{array}$
\end{tabular}

What is the role of patient autonomy in public health emergencies? Under normal circumstances, if a reasonable patient prefers surgery for cancer, and the treatment is indicated, then they are booked on a theatre list. However, patient autonomy is diminished in public health emergencies as health care ethics shifts priority to populations over individuals.

Essential cancer surgery has been restricted to a minimum reasonable allotment in accordance with national and international guidelines and regulations during the COVID-19 pandemic, rather than to higher volumes. If new data demonstrate that the restriction of essential cancer surgery causes the loss of more life years than COVID-19 patients, should health care services be reallocated to patients requiring essential cancer surgery? Maximizing the benefits of any decision, that is, doing whatever will potentially save the most lives, is most important.

It is imperative to reflect that COVID-19 is neither the first nor will it be the last public health emergency to strain health care resources and potentially place health care professionals and patients at an increased risk. The need to carefully consider underlying treatment goals, patient health issues, health care professional risk and institutional resources in triaging procedures is in some ways comparable to experiences during the early years of the human immunodeficiency virus epidemic.

\section{Sword of Damocles}

It must also be recognized that there may be more cancer deaths than COVID-19 deaths next year, even if deaths from COVID-19 reach the level of the highest projections [8]. If essential cancer surgery is not provided to patients, the cancer death rate will climb even higher. Furthermore, COVID-19 will likely persist for many months if not years into the future, until a vaccine becomes available or sufficient infection occurs in the population to achieve herd immunity [9]. Therefore, there is an ongoing need to continue to provide essential cancer surgeries for patients who need them [9].
Conflict of interest S. Al-Benna declares that he has no competing interests.

\section{References}

1. Al-Benna S. Concepts of management of plastic surgery services during the coronavirus disease 2019 pandemic. Eur J Plast Surg. 2020; https://doi.org/10.1007/s00238020-01704-1.

2. Al-Benna S. Management of hand surgery services during the coronavirus disease 2019 pandemic. JHand Microsurg. https://doi.org/10.1055/s-0040-1714440

3. Al-Benna S. Availability of COVID-19 information from national and international aesthetic surgery society websites. Aesthetic Plast Surg. 2020;44(3):1043-6. https://doi.org/ 10.1007/s00266-020-01751-w.

4. Al-Benna S, Gohritz A. Availability of COVID-19 information from national plastic surgery society websites. Ann Plast Surg. 2020; https://doi.org/10.1097/SAP. 0000000000002447.

5. Al-Benna S, Steinstraesser L. Postablative reconstruction is better terminology than oncoplastic surgery. Plast Reconstr Surg. 2009;124(6):463e-4e.

6. Emanuel EJ, Persad G, Upshur R, et al. Fair allocation of scarce medical resources in the time of covid-19. N Engl J Med. 2020;382(21):2049-55. https://doi.org/10.1056/ NEJMsb2005114.

7. Intensive Care National Audit \& Research Centre (ICNARC). Report on COVID-19 in critical care. 08 May 2020. 2020. https://www.icnarc.org/DataServices/ Attachments/Download/b8c18e7d-e791-eal1-602912500505601089b. Accessed 15 May 2020.

8. Lai A, Pasea L, Banerjee A, et al. Estimating excess mortality in people with cancer and multimorbidity in the COVID19 emergency. Apr 2020. https://www.researchgate.net/ publication/340984562_Estimating_excess_mortality_in_ people_with_cancer_and_multimorbidity_in_the_COVID19_emergency. Accessed 15 May 2020.

9. Al-Benna S. Impact of COVID-19 on surgical registrars' education and training. SAfr J Surg. 2020;58(2):10-3.

Publisher's Note Springer Nature remains neutral with regard to jurisdictional claims in published maps and institutional affiliations. 